\title{
Course Teaching Reform and Practice of Properties of Material Based on Flipped Classroom from the Perspective of "Golden Course"
}

\author{
Peng Fu, Wei Li, Jigong Hao, Yibin Yin, Changzheng Wang \\ (School of Materials Science and Engineering, Liaocheng University, Liaocheng, Shandong, 252059, China)
}

\begin{abstract}
This paper analyzes the development status of the golden course and flipped classroom teaching model, discusses the problems in the course construction of Properties of Material, reveals the significance of the teaching reform and practice of flipped classroom on the "golden course" construction of Properties of Material, and discusses the teaching reform and practice process and methods of Properties of Material based on flipped classroom, and conducts in-depth analysis of various methods to achieve better teaching achievements.

Keywords: golden course; flipped classroom; Properties of Material; teaching reform; practice

*The first (corresponding) author: Fu Peng, male, Associate Professor, $\mathrm{PhD}$, mainly engaged in research of information functional materials.

Fund Project: I would like to express my sincere appreciation to the following, Liaocheng University's teaching reform research project "Course Teaching Reform and Practice of Properties of Material Based on Flipped Classroom from the Perspective of "Golden Course" (No.: G201901z) and Liaocheng University's experimental technology research project "Application of Scientific Research Achievements in the Experimental Teaching of Piezoelectric Ceramic Preparation and Testing" (No. 26322170204), who have offered supports to this research.
\end{abstract}

DOI: $10.36012 /$ fhe.v2i1.1567

\section{Introduction}

I n August 2018, the Ministry of Education of the People's Republic of China issued the Notice on Vigorously Implementing the Spirit of the Undergraduate Education Work Conference of National Colleges and Universities in the New Era, proposing that "Each college and university should comprehensively sort out the teaching content of each course and enhance the academic challenges of students, reasonably increase the difficulty of the course, expand the depth of the course, expand the selectivity of the course, eliminate the "water course", and create golden courses with high order, innovation and challenge. In 2019, the Ministry of Education initiated the "Golden Course Construction" plan, which has revolutionized the quality of higher education. Now, "Golden Course" has become one of the most important keywords for China's higher education reform in the new era ${ }^{[1-3]}$.

In recent years, many colleges and universities have begun to focus on and vigorously develop the teaching research and practice of flipped classroom, which is a revolution in student-centered learning and teaching methods. Now, it has been proved that flipped classroom is an effective teaching method to stimulate students' interest in learning and achieve the goal of training innovative talents ${ }^{[45]}$. The implementation of flipped classroom can expand the time and space for students to learn and students can complete the self-study of some knowledge points through the learning resources provided by the teachers before the class. In flipped classroom, a variety of curriculum practices and seminars are carried out to cultivate students' comprehensive ability to solve complex prob- 
lems and advanced thinking. Therefore, flipped classroom teaching model is very in line with the development requirements of the "Golden Course" construction.

Properties of Material, as a core course of the first-level discipline of materials science and engineering, can train students to have the necessary basic knowledge and basic skills for rational selection of materials and the development of new materials. So, it is of great significance in the undergraduate materials major. In the context of the "Golden Course", colleges and universities have made corresponding improvements to the teaching content, teaching methods, and teaching goals of Properties of Material. teachers such as Lin Bilan of Xiamen University of Technology and Sun Hao of Inner Mongolia University of Science \& Technology ${ }^{[6-7]}$ adopted case teaching method in the course teaching of Properties of Material by, which not only increased the interest of students, but also guided students to select and use materials according to the actual situation, bringing a good enlightenment on the cultivation of applied talents. Teachers such as Li Hui, Tian Zhongqing of Chongqing University of Technology, and Guan Lei of Liaoning Shihua University ${ }^{[8-10]}$ have improved students' practical innovation ability by improving the teaching methods and content of Properties of Material. However, at present, the teaching and research of Properties of Material is lacking in the research and implementation of flipped classroom, and there is no report yet.

\section{Problems encountered in the "Golden Course Construction" of the course Proper- ties of Material}

In recent years, although we have achieved certain results in the course construction of Properties of Material, we also realize that there is still a gap between the requirements of the course Properties of Material and golden courses, and there are still the following defects:

(1) The teaching content lacks innovation and challenge: The teaching knowledge system lags behind the latest level of current scientific research development, and is not advanced and modern enough; the teaching content is unreasonable, the students are not thinking enough, which is very unfavorable for students to track and master the development status and trend of theory, and it is difficult for students to adapt to future study and work demands.
(2) The teaching form is not progressive and interactive enough: Teachers usually teach content in the class, students passively absorb knowledge passively, which is not interactive enough; The new technologies, new methods and teaching tools developed in the information age have not been applied into teaching. For example, video, animation, WeChat platform, network platform and some learning software, etc. have not been or are not proficiently applied and there is no online learning communication in different environments anytime and anywhere.

(3) The course teaching is not advanced enough: In teaching, the integration of knowledge, ability and quality is not enough, resulting in a serious lack of students' ability to analyze and solve practical application problems and advanced thinking, which cannot meet the social needs of materials talents.

\section{The significance of teaching reform and practice of flipped classroom to the course construction of this course}

According to the analysis of the above problems, the teaching reform and practice of golden course oriented flipped classroom in the teaching of the course Properties of Material are of great significance to the construction of the golden course and the cultivation of students' quality in this course:

3.1 Flipped classroom teaching model can make the teaching content advanced and modern enough

Flipped teaching requires teachers to do pre-class teaching design, introduce relevant latest research trends at home and abroad, and introduce the frontiers of international academic research to the students based on their own research projects to improve the course and challenge; By introducing practical engineering cases into the course, students can be guided to analyze practical engineering problems with the knowledge of properties of material to improve the breadth of the course, thus creating a "golden course" of Properties of Material with depth, height, breadth and is advanced and modern enough.

\subsection{Flipped classroom teaching method is an im-} portant measure to realize advancement and interactivity

The teaching of Properties of Material has been dominated by traditional classroom education for a long time, and the flipped classroom teaching can realize the transformation from the traditional "static, passive, 
personal, and accepting" teaching paradigm of "teaching as the center" to the new "interactive, participating, cooperative, and exploratory" paradigm of "learning as the center".

3.3 Flipped classroom teaching model is conducive to the cultivation of comprehensive ability and advanced thinking

Flipped teaching is helpful for students to systematically understand the essential problems of properties of material and analysis methods, and it is easy to guide students to establish the organic correlation of several elements of material composition and structure, synthesis and processing, nature and properties to train students to have the necessary basic knowledge and basic skills for rational selection of materials and the development of new materials.

3.4Flipped classroom teaching is conducive to playing the role of informatization in education

In the course of teaching, use ANSYS and refined software to simulate and analyze the structure, properties and engineering problems of materials. With the help of software, the abstract concepts are visually displayed, which is easy for students to understand and can cultivate students' ability to solve practical engineering problems with software; While, the construction of network teaching platform and the application of learning software will widen students' learning space and effectively improve the quality of "golden course".

In summary, through the construction of the gold course of this course and the implementation of the flipped classroom teaching model, it is not only conducive to the cultivation of high-quality material talents, but also is expected to make a breakthrough in the theoretical system in the construction of "gold course" and is of great significance.

\section{Teaching reform and practice of flipped classroom of Properties of Material}

4.1 Upgrade the course standard under the "Gold Course" standard

The course standard of Properties of Material currently used has been difficult to adapt to the current requirements for the cultivation and teaching development of materials professionals. To this end, we have developed an interactive and exploratory talent training model and course standards that highlight comprehensive capabilities, combine theory with practice, and take "learning as the center" to organically integrate training objectives and content with knowledge, abilities, and qualities to develop students' comprehensive ability and advanced thinking in solving complex problems.

\subsection{Renovation of flipped classroom teaching con-} tent and knowledge system

With the purpose of reflecting the high order, innovation and challenge of the "Golden Course", we studied how to realize the renovation of the teaching knowledge system.

\subsection{Knowledge system expansion of teaching mate- rials}

At present, the textbook we use is Properties of Material by Beijing University of Technology Press. This textbook is relatively comprehensive and covers both the mechanical properties and physical properties with clear structures and rich contents. In the teaching, we find that when other versions of the textbooks are used to teach some content, the content displayed is richer, more direct, and easier to understand, so our teaching materials introduce the content of other textbooks.

\subsection{Research on the effect of scientific research on teaching}

Scientific research not only can exercise innovation ability and update knowledge structure, but also is an indispensable part of enhancing teaching depth and expanding teaching breadth. We studied how to apply scientific research achievements related to the course knowledge system to teaching. For example, our college has many research achievements in piezoelectric and ferroelectric materials. In the teaching, we apply the relevant achievements to the explanation of "piezoelectricity and ferroelectricity" in a timely manner, so that students can grasp the latest trends in this field and understand the latest theoretical knowledge system. At the same time, students are encouraged to actively review the latest literature to understand the development status of materials with different properties.

\subsection{Strengthen the integration of knowledge be-} tween different courses

In order to reflect the breadth and depth of the "golden course" requirements, in the teaching of Properties of Material, we studied the relevance of the courses completed by students, such as Fundamentals of Materials Science, Solid State Physics and College Physics, etc., to this course, and introduced them into the classroom to guide students to understand relevant knowledge of 
properties of material.

\section{Construction of the flipped classroom teaching model from the perspective of the golden course}

Classroom teaching is the main part for the construction of "Golden Course". We take the teaching design and implementation effects of flipped classroom as the main line to build a new interactive, participating, cooperative, and exploratory model with learning as the center.

\subsection{Overall design of the teaching content}

Flipped classroom is an effective strategy and method of online and offline mixed teaching, mainly using the "pre-class video + class discussion" model. First of all, from the perspective of teaching resources, the most critical teaching resource for flipped classroom teaching model is the micro-course. The micro-course video we recorded in the early stage is generally about 10 minutes, which leaves enough time for students to think and record the key points by means of pausing playback and playback. Students can also study independently in their spare time.

Secondly, from the perspective of the role of teachers and students, under the flipped classroom teaching model, the teachers are no longer the passive imparters of knowledge and the complete classroom leader, but students are the main body of the classroom. At this time, teachers exist only to help and guide students, and students gradually become active learners and researchers from the original passive receivers, which forms a student-centered and student-oriented classroom pattern, which significantly improves the pertinence and independence of classroom teaching.

\subsection{Construction of flipped classroom teaching model}

Flipped classroom studies mainly include the tasks of the three teaching stages of "before class-in class-after class", the main methods are as follows:

(1) Self-study before class: Before the class, our teachers will release pre-class tasks and materials based on the teaching content. Students can learn the content of this class in advance through micro-videos, electronic teaching plans, PPT or special knowledge explanation on the online teaching platform, and record the problems encountered in the study and bring them to class for discussion.
(2)Classroom discussion and analysis: We will review and discuss the pre-lesson content with all students in an interactive way to strengthen students' impression of new knowledge and concepts. In our teaching activities, we focus on "example guidance - problem-driven - ability-oriented - application development", and increase the participation and liveness of students and achieve the goal of solving problems through issue-driven interaction, questioning and discussion between students and between students and teachers through project examples.

(3) Summary and improvement after class: After class, students can expand and improve through comprehensive exercises, network interaction and individual counseling. At the same time, they can further summarize the knowledge in the class, summarize the problems again in practice, and communicate with teachers or classmates to actively improve the deficiencies in the above links and form a good circulation mechanism.

\section{Development and use of teaching software or network platform}

The large-scale promotion and use of the social network technology, computer information technology, etc., provides favorable technical conditions for the implementation of the flipped classroom teaching model, and is also a necessary condition for the flipped classroom teaching model. In the teaching, we introduce or develop and use Flash animation, video, simulation software, etc. to allow students to understand relevant knowledge more directly. We have also initially established convenient and fast WeChat learning platforms where students can watch course videos and communicate online at any time.

\subsection{Combining theoretical teaching and practical teaching to make the "Golden Course" challenging enough}

In order to cultivate students' problem-solving ability and advanced thinking, we strengthen our efforts to guide students to apply for and participate in various college students' innovation and entrepreneurship projects, and make students have the opportunity to prepare materials through experiments, conduct material performance tests and other work. The Properties of Material we set up plays a very good guiding role. We guide students to link the content of the textbook with practice, greatly improving the challenge of the course 
and improving students' comprehensive problem-solving ability. In addition, in theoretical teaching, we combine the professional experiments set up to conduct research on the combination of theory and practice, which not only deepens students' understanding of professional experiments, but also helps to understand the theoretical knowledge of Properties of Material.

\subsection{Construct a flipped classroom assessment mechanism and evaluation mechanism}

Based on the course evaluation method of the flipped classroom, we have established a multi-element score evaluation system, and abandoned the evaluation method through examination paper. On the premise of ensuring that the students have comprehensively mastered the basic knowledge, the students' ability to find problems, think about problems, solve problems and their ability to learn independently is the focus of our evaluation. At the same time, the evaluation method based on the flipped classroom should be a multi-dimensional evaluation system that comprehensively evaluates the performance of students in teaching activities and learning activities. In addition, we studied the evaluation indicators that need to be designed at each stage before, during and after the class. Through online and offline interaction, evaluation and discussion, we evaluated the completion of students' tasks at each stage and gave evaluation scores according to the communication results.

After the preliminary course construction, we designed and developed the course resources such as micro-courses and courseware of Properties of Material and WeChat public account and other network platforms, and constructed the three-stage task and evaluation mechanism of "before class-in class-after class", initially created a "golden course" standard flipped classroom teaching model, promoted the continuity of learning before and after class through the reflection on the teaching process and effect, and initially established a dynamic adjustment mechanism for flipped classroom teaching, and thus improved teachers' teaching level and students' comprehensive ability to solve complex problems and advanced thinking.

\section{References}

[1] Wang Yunwu, Huang Ronghuai, Peng Zihan, Zhang Yao, Xu Yi, Creating the New Chinese "Golden Course" to Train "Excellent and Top-notch" Talents, China Medical Education Technology, 2019,33(4):379-384.

[2] Wu Xiaosheng, Li Jing, "New Media Technology and Application" Practice Teaching Reform under the Golden Course Standard, Journal of Chizhou University, 2019,33 (3):145-147.

[3] Lv Yanan, Discussion on how to Build an Offline Golden Course, The Guide of Science \& Education,2019,18:47-49.

[4] Xie Hongmei, Geng Kuihua, Analysis of the Flipped Classroom Teaching Model of the Course of Mechanical Principles, Journal of Higher Education,2019,17:112-115.

[5] Zhao Shumin, Research on Flipped Classroom for Deep Learning, Journal of Tianjin Normal University,2019,20(4): 71-73.

[6] Lin Bilan, Application of Case Teaching Method in the Teaching of Properties of Material, China Metallurgical Education,2014,26-28.

[7] Sun Hao, Li Tao, Wu Zhongwang, Application of Case Teaching in Properties of Material, China Modern Education Equipment,2016,2:71-73.

[8] Li Hui, Tian Zhongqing, Zhang Chunyan, Reform and Thinking of the Teaching Content and Teaching Methods of Properties of Material, Guangzhou Chemical Industry, 2016,2:181-182.

[9] Tian Zhongqing, Application of Mind Maps in the Course of Properties of Material, Shandong Chemical Industry, 2015,44:128-129.

[10] Guan Lei, Wang Ying, Discussion on the Application of Multi-dimensional Teaching Method in the Teaching of Properties of Inorganic Material, Theory and Practice of Contemporary and Education, 2014,6:64-65. 